\title{
Energetic cost of photoinhibition in corals
}

\author{
Mia O. Hoogenboom*, Kenneth R. N. Anthony, Sean R. Connolly \\ ARC Centre of Excellence for Coral Reef Studies, and School of Marine Biology and Aquaculture, \\ James Cook University, Townsville, Queensland 4811, Australia
}

\begin{abstract}
Photoinhibition may constitute an energetic cost for photosynthetic organisms through damage to the photosynthetic apparatus, or by increased metabolism due to damage avoidance or repair. For several species of scleractinian corals, fluorescence techniques have revealed a significant reduction in photochemical efficiency of symbiotic dinoflagellates within coral tissue in response to excess light absorption. To date, it has been unclear whether or not photoinhibition has a negative impact on energy budgets in corals. We simultaneously quantified the effect of exposure to excessive light on net rates of photosynthesis and on fluorescence-derived photochemistry. We acclimated colonies of the reef-building coral Turbinaria mesenterina to 3 different irradiance regimes in the laboratory. The corals were then exposed to light levels up to 10 times higher than their acclimation irradiance and assayed for rates of photosynthesis and photochemical yields. Results indicated that daily costs of photoinhibition are negligible. Reduced net rates of photosynthesis in the afternoon, compared to the morning, were predominantly due to enhanced afternoon rates of dark respiration. However, photoacclimation to high light levels reduces daily energy acquisition in the long term, primarily due to decreased chlorophyll concentrations. Therefore, although changes in the photosynthetic activity of symbiotic dinoflagellates over a diurnal irradiance cycle do not cause a measurable decline in net oxygen evolution for coral colonies, repeated exposure to excessive irradiance can reduce energy acquisition per unit surface area, and hence influence the upper limit of the depth distribution of scleractinian corals.
\end{abstract}

KEY WORDS: Photoinhibition · Respirometry $\cdot$ PAM fluorescence · Scleractinian coral · Energy budget . Photosynthetic efficiency - Turbinaria mesenterina

Resale or republication not permitted without written consent of the publisher

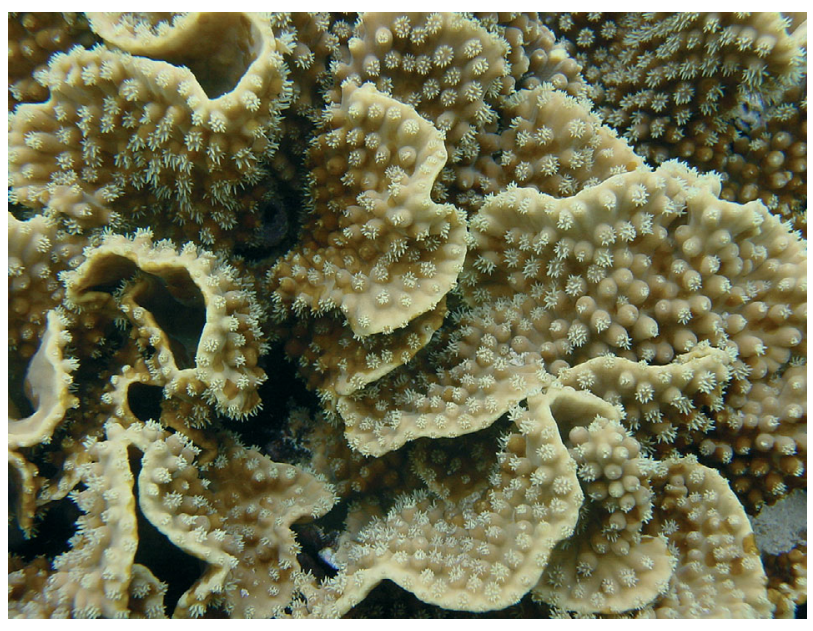

The scleractinian coral Turbinaria mesenterina is abundant on inshore reefs, where light regimes are highly variable. Conspicuous pale patches may develop on the colony surface following repeated exposure to very high light levels. This represents an energetic cost of excessive light exposure (photoinhibition) that becomes apparent over a time scale of several days.

Photo: Dr. Andrew Baird, ARC Centre of Excellence for Coral Reef Studies, Townsville, Australia

\section{INTRODUCTION}

Increasing irradiance leads to a saturation of photosynthesis (Falkowski \& Raven 1997), and at high irradiances, excessive light absorption can damage the photosynthetic apparatus or, alternatively, induce physiological processes that dissipate energy before damage can occur (Demmig-Adams \& Adams 1992). This phenomenon, photoinhibition, results in a 6 to $25 \%$ decline in daily carbon gain in higher plants and phytoplankton (Ogren \& Sjostrom 1990, Pahl-Wostl 
1992, Werner et al. 2001), leading to reduced growth rates (Laing et al. 1995). For numerous scleractinian coral species, a marked reduction in the efficiency of light use for photochemistry by zooxanthellae, the symbiotic dinoflagellates within coral tissue, is apparent under high light conditions (e.g. Brown et al. 1999, Jones \& Hoegh-Guldberg 2001, Winters et al. 2003). Furthermore, when isolated from their coral host, zooxanthellae exhibit reduced rates of photosynthesis at high light levels (Shick et al. 1995, Goiran et al. 1996; but see Iglesias-Prieto \& Trench 1994). Correspondingly, avoidance of excessive light levels is a determinant of morphology in coral colonies, and many species generate self-shading morphologies in high-light habitats (Oliver et al. 1983, Titlyanov 1991a, Muko et al. 2000). Despite this, the impact of photoinhibition on net rates of photosynthetic energy acquisition of the coral symbiosis is not well understood. If photoinhibition incurs significant costs for corals, it may exclude light-sensitive species from shallow habitats. Even in the presence of morphological strategies that reduce light absorption, or potential changes to the composition of the symbiont population toward light-tolerant clades (e.g. Iglesias-Prieto et al. 2004), costs of photoinhibition potentially demarcate an upper bound of the depth distribution of reef-building corals.

Using $\mathrm{O}_{2}$ or $\mathrm{CO}_{2}$ flux measurements (respirometry), photoinhibition has traditionally been detected as a decline in the light-saturated photosynthetic rate (e.g. Platt et al. 1980). An alternative method for assaying photosynthesis is fluorometry, which allows estimates of photosynthetic activity from the fluorescent properties of chlorophyll in vivo (Maxwell \& Johnson 2000). In the fluorometry method, photoinhibition is typically inferred from a decline in photochemical efficiency during and/or after exposure to high irradiance. Such a decline may be due to reversible processes such as increased dissipation of absorbed light as heat ('dynamic' photoinhibition), or to damage to photosynthetic units requiring de novo synthesis of protein for repair ('chronic' photoinhibition: Hoegh-Guldberg \& Jones 1999, Gorbunov et al. 2001). In corals, changes in photochemical yield of zooxanthellae over a diurnal irradiance cycle are generally attributed to dynamic photoinhibition (Hoegh-Guldberg \& Jones 1999, Lesser \& Gorbunov 2001, Winters et al. 2003). However, chronic photoinhibition has also been reported, with up to $30 \%$ of photosynthetic reaction centers damaged by exposure to full sunlight in shallow waters (see Gorbunov et al. 2001). Nevertheless, there is no evidence to indicate whether such changes in photochemistry of zooxanthellae lead to reduced photosynthetic energy acquisition of the coral symbiosis. In some corals, rates of photosynthetic oxygen evolution are higher in the afternoon than in the morning (Levy et al. 2004), even though photoinhibition should be greater in the afternoon following exposure to high irradiance at midday. To determine the ecological significance of photoinhibition for reef-building corals, we must resolve whether excess light absorption entails an energetic cost, and, if so, whether this cost constitutes a significant proportion of daily photosynthetic energy acquisition.

Photoinhibition, whether dynamic or chronic, may comprise an energetic cost by reducing the maximum rate of photosynthesis $\left(P_{M A X}\right)$ at supra-saturating light levels (e.g. Platt et al. 1980). Alternatively, costs may arise from increased sub-saturation irradiance $\left(E_{K}\right)$ following exposure to high irradiance, corresponding to lower efficiency of light utilization for photosynthesis (e.g. Kana et al. 2002). Finally, photoinhibition may cause elevated rates of respiration $\left(R_{D A R K}\right)$ due to increased biosynthesis for damage repair.

The principal aim of this study was to resolve whether photoinhibition comprises a significant energetic cost for corals. Our focus was upon costs incurred by the coral/zooxanthellae symbiosis, the ecologically relevant unit of study for analyses of energy budgets for coral colonies. We quantified the cost of photoinhibition through changes in the parameters of the diurnal photosynthesis-irradiance (PI) relationship of corals. Given the influence of photoacclimation on the shape of the PI curve (e.g. Anthony \& Hoegh-Guldberg 2003), we calculated costs of photoinhibition for corals acclimated to 3 different light regimes and exposed to 2 different diurnal irradiance cycles. In all cases, we expected that changes in photosynthesis parameters would be most pronounced for corals acclimated to lower light levels.

Our second aim was to evaluate the functional relationship between fluorescence and oxygen respirometry as assays of photosynthesis in reef-building corals. Respirometry and fluorometry measure different aspects of the PI relationship: the former captures net photosynthetic gas exchange averaged over a photosynthetic surface and the latter indicates gross photosynthetic electron transport from a small area of that surface (e.g. Maxwell \& Johnson 2000). One of the key validations for the use of fluorescence as a measure of photosynthesis is proportionality between the quantum yields (photosynthesis per unit light absorbed) of oxygen evolution and photochemistry (e.g. Brown et al. 1999). Although a linear relationship between these variables has been established experimentally for some plants (Genty et al. 1989, Maxwell et al. 1998), field-based measurements often reveal a non-linear relationship (e.g. Seaton \& Walker 1990, Fryer et al. 1998). This non-linearity means that gross photochemical activity may vary considerably without having any effect on net rates of photosynthesis. For 
corals, the functional relationship between Photosystem II (PSII) photochemistry and oxygen evolution is unknown. This is significant, because properties of the coral/zooxanthella symbiosis may cause this relationship to diverge considerably from that demonstrated for higher plants (e.g. due to respiration of coral tissue independently of photosynthetic production by symbionts).

\section{MATERIALS AND METHODS}

We used the foliose coral Turbinaria mesenterina (Dendrophyllidae) as our study species, because it generates self-shading colony morphologies in high light habitats, suggesting sensitivity to excess light absorption (Willis 1985, Anthony et al. 2005). We collected 36 flat fragments (measuring approximately $10 \times 10 \mathrm{~cm})$ from deep (6 m depth) and shallow (1 m depth) sites at Nelly Bay, Magnetic Island (1909' S, $146^{\circ} 53^{\prime} \mathrm{E}$ ) on 15 April 2004. Colonies were transported to aquarium facilities at James Cook University, divided into groups and allowed to photoacclimate to 3 different irradiance regimes - 'High', 'Medium' and 'Low' - which corresponded to maximum daily irradiances of 570, 270 and $120 \mu \mathrm{mol}$ photons $\mathrm{m}^{-2} \mathrm{~s}^{-1}$ and represent 4,7 and $10 \mathrm{~m}$ depth at the collection site, respectively (M. O. Hoogenboom unpubl. data). We used a minimum experimental depth of $4 \mathrm{~m}$, as previous attempts to photoacclimate flat fragments of the study species to higher light levels resulted in high mortality (K. R. N. Anthony unpubl. data). This makes our results conservative with respect to the prevalence of photoinhibition under field conditions, as all colonies were acclimated to relatively low light levels. Colonies were allowed $6 \mathrm{wk}$ for recovery and photoacclimation, which is ample for this species (Anthony \& Hoegh-Guldberg 2003). To avoid potential changes to photosynthetic properties of our corals due to nutrient limitation, colonies were fed live rotifers (50 rotifers $\mathrm{ml}^{-1}$ ). Water temperature was maintained between 26.5 and $28^{\circ} \mathrm{C}$, approximating the modal temperature at the collection site $\left(\approx 27^{\circ} \mathrm{C}\right.$, AIMS Cleveland Bay Weather Station Data).

Experimental setting. An array of 6 closed, clearperspex incubation chambers $(2.7$ l) coupled with calibrated Clark-type oxygen electrodes (Cheshire Systems) was used for the oxygen respirometry assays. The chambers were designed as flumes, equipped with pumps to maintain continuous water circulation at 5 to $6 \mathrm{~cm} \mathrm{~s}^{-1}$ (laminar flow), and were flushed for $4 \mathrm{~min}$ in every 20 min measuring period to prevent oxygen super-saturation. To control for photosynthesis and respiration of microorganisms within the water, we regularly left 1 chamber empty during respirometry runs. In addition, chambers were cleaned at the end of each run to prevent biofilm formation. Oxygen concentrations were recorded every 20 s using a data logger (CR10X, Campbell Scientific). We suspended 400 W metal halide lamps (Eye) above both the chambers and aquaria to provide the light source for both diurnal photosynthesis measurements and the light acclimation treatments. These lamps have a spectrum resembling natural sunlight with the ultraviolet component present. For the photosynthesis measurements, we varied irradiance over the course of the day by changing the elevation of the lamps every $20 \mathrm{~min}$, during the flushing period. Light levels (downwelling PAR) were measured using a cosine-corrected Licor probe (Li-192S) connected to a Li-1000 data logger (Licor). The chambers were submerged in a $1000 \mathrm{l}$ water jacket with running seawater connected to a temperature control unit (C023, Carrier Systems) to prevent changes in water temperature during the measurement period.

On each day of data collection, 5 to 6 colonies from a photoacclimation treatment were selected for oxygen evolution measurements. Photosynthesis versus irradiance curves (PI curves) were constructed over $10 \mathrm{~h} \mathrm{di-}$ urnal cycles, with irradiance at time $t, E(t)$, varying approximately according to a cubic sine function: $E(t)=$ $E_{M A X} \sin ^{3}(\pi t / d)$, where $t$ is time (h after dawn), $d$ is day length $(10 \mathrm{~h})$ and $E_{M A X}$ is maximum daily irradiance. This function closely approximates diurnal irradiance variation under natural aquatic conditions (Marra 1978). Dark respiration was measured twice each day, at the beginning and end of each respirometry run. PI curves were measured on consecutive days with $E_{\text {MAX }}=$ $600 \mu \mathrm{mol}$ photons $\mathrm{m}^{-2} \mathrm{~s}^{-1}$ on Day 1 and $1200 \mu \mathrm{mol}$ photons $\mathrm{m}^{-2} \mathrm{~s}^{-1}$ on successive days. We used different diurnal irradiance cycles to assess whether costs of photoinhibition were influenced by the degree to which experimental irradiance exceeded the growth (acclimation) irradiance. For the corals acclimated to low light, we repeated measurements at $E_{M A X}=1200 \mu \mathrm{mol}$ photons $\mathrm{m}^{-2} \mathrm{~s}^{-1}$ over $3 \mathrm{~d}$ to determine how photosynthetic properties change through time under potentially photoinhibitory conditions. To relate oxygen flux to colony tissue surface area, colonies were photographed together with a ruler using a digital camera (Canon G3). Surface areas were later determined using Image Tools (University of Texas Health Science Centre).

At the same time as colonies were selected for $\mathrm{O}_{2}$ evolution measurements, an identical set of colonies was selected for fluorescence measurements, and positioned outside the respirometry chambers. Irradiance at the surface of colonies inside and outside the chambers varied $<5 \%$. Fluorescence assays were carried out using a pulse-amplitude-modulated fluorometer (Mini-PAM, Walz) fitted with a $5 \mathrm{~mm}$ fiber optic probe. At the end of each 20 min illumination period, fluo- 
rescence was measured at the centre of each colony. Apparent quantum yield of photochemistry $\left(\Delta F / F_{m}{ }^{\prime}\right.$, dimensionless) was calculated as $\Delta F / F_{m}{ }^{\prime}=\left(F_{m}{ }^{\prime}-F\right) / F_{m}{ }^{\prime}$, where $F$ is steady state fluorescence in the light and $F_{m}$ ' is maximal fluorescence in the light (Genty et al. 1989). Similarly, maximum quatum yield $\left(F_{V} / F_{m}\right.$, dimensionless) was calculated as $F_{V} / F_{m}=\left(F_{m}-F_{o}\right) / F_{m}$ where $F_{o}$ and $F_{m}$ are steady state and maximal fluorescence iin darkness, respectively. We also calculated a non-photochemical quenching coefficient as NPQ $=\left(F_{m}-F_{m}{ }^{\prime}\right) / F_{m}{ }^{\prime}$ (after Maxwell \& Johnson 2000). Yield measurements were converted to relative electron transport rates (rETR) using the formula $\mathrm{rETR}=\Delta F / F_{m}{ }^{\prime} \times E \times 0.5$, where $E$ is irradiance and 0.5 is a factor that accounts for the distribution of electrons between Photosystem I and PSII (e.g. Hoegh-Guldberg \& Jones 1999). We used this relative measure of the rate of electron transport, as the light absorption characteristics of tissue are unknown for this species.

Chlorophyll concentration. Immediately after photosynthesis assays were completed, colonies were frozen at $-40^{\circ} \mathrm{C}$ and later used to determine chlorophyll content. Colonies were broken into 2 fragments and photographed for surface area measurements (see above). Fragments were ground to a fine paste, and chlorophyll was extracted in the dark using cold acetone $(100 \%)$. To ensure that all chlorophyll was extracted from each coral fragment, the initial overnight extraction (12 h) was followed by two $1 \mathrm{~h}$ extractions. The combined volume of all 3 extractions was measured, and the extract centrifuged; 10 replicate absorbance readings at 630 and $663 \mathrm{~nm}$ were carried out for each fragment, and concentration of chl $a$ and chl $c 2$ was determined using the equations of Jeffrey \& Humphrey (1975). Chlorophyll concentrations were then normalised to fragment surface area.

Data analysis. We fitted a hyperbolic tangent function (Eq. 1) to PI data in order to estimate $P_{M A X}$ (maximum rate of photosynthesis, $\mu \mathrm{mol} \mathrm{O}_{2} \mathrm{~cm}^{-2} \mathrm{~h}^{-1}$ ) and $E_{K}$ (sub-saturation irradiance, $\mu \mathrm{mol}$ photons $\mathrm{m}^{-2} \mathrm{~s}^{-1}$ ) using measured values of $R_{D A R K}$ (rate of respiration in darkness, $\mu \mathrm{mol} \mathrm{O}_{2} \mathrm{~cm}^{-2} \mathrm{~h}^{-1}$ ):

$$
P(E)=P_{M A X} \tanh \left(\frac{E}{E_{K}}\right)-R_{D A R K}
$$

We fitted this function to data using a LevenbergMarquardt non-linear estimation routine in STATISTICA (StatSoft). We first estimated $P_{M A X}$ and $E_{K}$ for the morning part of the diurnal photosynthesis curve. As there was no evidence in the data of a change in (net) $P_{M A X}$ in the afternoon compared with the morning, we subsequently used the fitted $P_{M A X}$ value from the morning part of the PI curve to obtain an estimate of $E_{K}$ during the afternoon. This allowed us to detect whether exposure to light over the course of the morning altered the shape of the PI curve during the afternoon. We used repeated-measures ANOVA to investigate the effect of photoacclimation state and diurnal irradiance cycle on changes in photosynthesis parameters over the day. We then used the fitted parameters to calculate photosynthetic oxygen evolution during mornings ( $5 \mathrm{~h}$ ) and afternoons (5 h), based on the integral of Eq. (1). We used a numeric integration routine in MATLAB (MathWorks) to evaluate this integral for each colony. Subsequently, we calculated the energetic cost of photoinhibition as the proportional difference between total photosynthesis summed over the morning, compared with the afternoon, and tested statistical significance of the cost by paired-samples $t$-tests. The cost therefore represents the reduction in net carbon acquisition due to exposure to excessive irradiance over a daily timescale. We chose this method in place of commonly used photosynthesis/respiration ratios (e.g. Muscatine et al. 1981), as rates of respiration over the day are not constant, as was assumed under the latter method (e.g. Kuhl et al. 1995, Al-Horani et al. 2003). To ascertain whether repeated exposure to excessive irradiance alters the photosynthetic properties of Turbinaria mesenterina, we used paired-samples $t$-tests to compare mean values of $5 \mathrm{key}$ photosynthetic properties between Days 1 and 3 of exposure.

Quantum yield of oxygen evolution, in mol oxygen (mol photons) $)^{-1}$, was obtained by dividing rates of photosynthesis (converted to appropriate units of $\mu \mathrm{mol} \mathrm{O}_{2} \mathrm{~m}^{-2}$ $\mathrm{s}^{-1}$ and corrected for dark respiration) by incident irradiance ( $\mu \mathrm{mol}$ photons $\mathrm{m}^{-2} \mathrm{~s}^{-1}$ ) (Seaton \& Walker 1990). Because dark respiration in corals is enhanced by light exposure (e.g. Edmunds \& Spencer-Davies 1988), we used linear interpolation between estimates of $R_{D A R K}$ for the morning and afternoon to convert measured net photosynthesis to estimates of gross photosynthesis. For comparison between fluorescence and respirometry assays of photosynthesis, we normalized our data to chlorophyll concentration. We chose this normalization to avoid confounding differences in photochemistry between light acclimation treatments with any differences in chlorophyll concentration.

\section{RESULTS}

\section{Net photosynthesis and rETR}

Photoinhibitory responses varied greatly, depending on whether respirometry or fluorescence assays of photosynthesis were used. In general, although rETR decreased under high irradiance in response to declining apparent photochemical yield (Fig. 1B,C), lightsaturated rates of photosynthesis remained constant for corals acclimated to all the 3 light regimes, regard- 

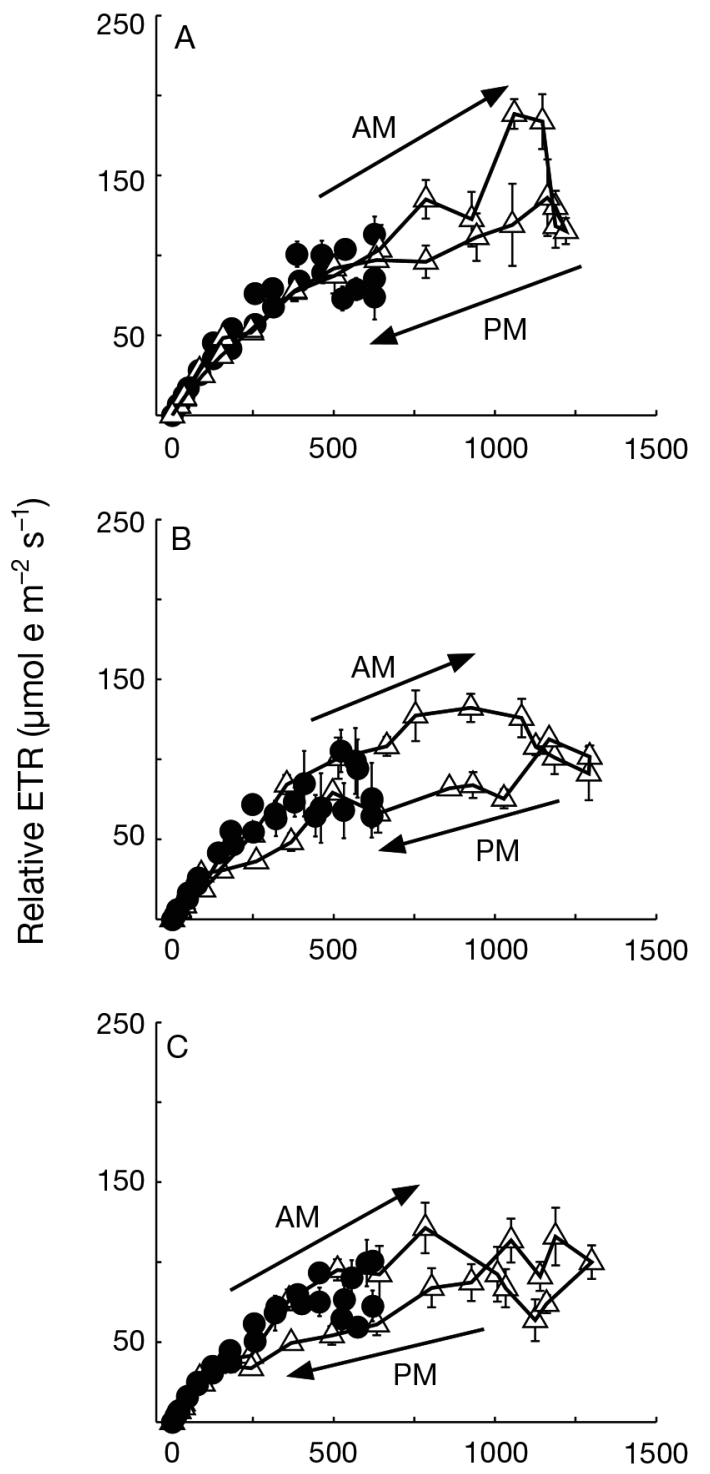
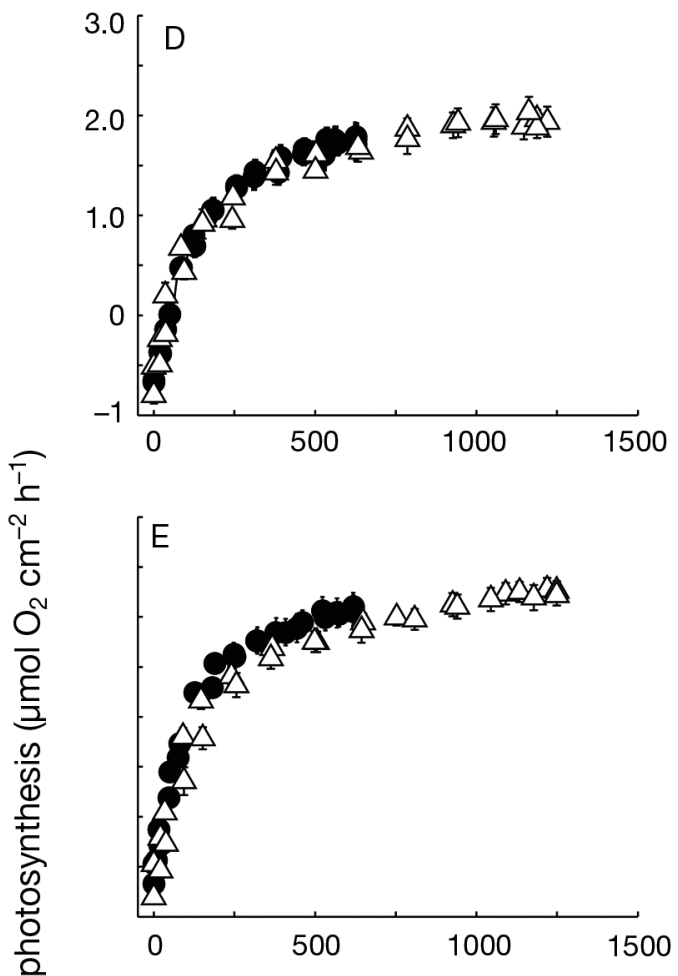

$\stackrel{+}{z}$

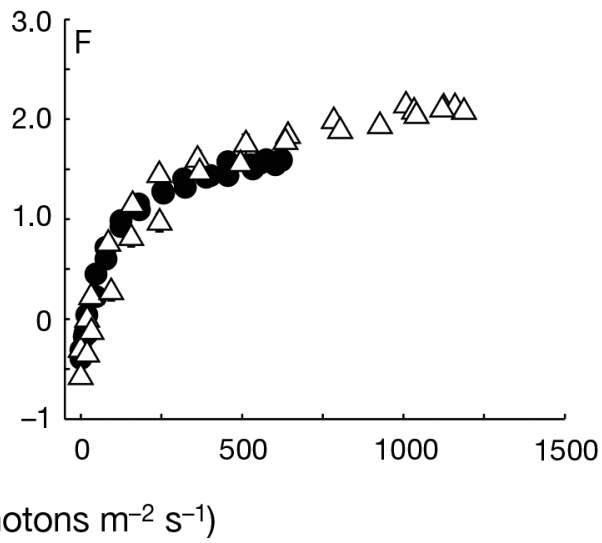

Fig. 1. Turbinaria mesenterina. Relative electron transport (rETR) and diurnal net photosynthesis versus irradiance in corals acclimated to 3 light regimes and subjected to 2 daily irradiance cycles $\left(\bullet: E_{M A X}=600 \mu \mathrm{mol}\right.$ photons m${ }^{-2} \mathrm{~s}^{-1} ; \Delta: E_{M A X}=1200 \mu \mathrm{mol}$ photons $\left.\mathrm{m}^{-2} \mathrm{~s}^{-1}\right)$, measured at 20 min intervals over the day; $(A, D)$ high light; $(B, E)$ medium light; $(C, F)$ low light $\left(\mathrm{mean} \pm S E_{;} n=5\right.$ to 8$)$

less of whether they were exposed to a daily irradiance cycle of $E_{M A X}=600$ or $1200 \mu \mathrm{mol}$ photons $\mathrm{m}^{-2} \mathrm{~s}^{-1}$ (Fig. 1D-F). For all of our light-acclimation treatments, NPQ was highest at midday, mirroring the decrease in photochemical yield (results not shown). The magnitude of NPQ was also related to photoacclimation state, with corals acclimated to high light showing greater quenching capacity. Compared with rates of oxygen evolution, rETR approached saturation more slowly and was generally higher in the morning than in the afternoon at the same irradiance. This effect was most apparent at mid-afternoon under both diurnal irradi- ance cycles, but rETR returned to morning levels by late afternoon. In other words, effects of photoinhibition on rETR were short-lived, and photochemical activity returned to initial values by the end of the day, despite exposure to light levels well above those to which corals were acclimated. Overall, we found no evidence that low photochemical efficiency at midday had any effect on net photosynthesis, i.e. although rETR via photochemistry decreased under high irradiance, rates of photosynthesis remained saturated even when corals were exposed to light levels much higher than their acclimation irradiance. 
Table 1. ANOVA for the effect of photoacclimation state (State), diurnal irradiance cycle (Treatment) and time of day (Time) on photosynthesis-irradiance curve parameters, and results of post hoc tests (Tukey's Unequal N HSD). $P_{M A X}$ : maximum rate of photosynthesis; $E_{K}$ : sub-saturation irradiance; $R_{D A R K}$ : rate of respiration in darkness. L, M, H: corals acclimated to low, medium and high irradiance regimes, respectively; 600/1200: estimates under daily irradiance cycles with $E_{M A X}=600$ and $1200 \mu \mathrm{mol}$ photons $\mathrm{m}^{-2} \mathrm{~s}^{-1}$, respectively. AM, PM: estimates from the morning and afternoon half of the diurnal photosynthesis curve

\begin{tabular}{|c|c|c|c|c|}
\hline Units & Effect & $F(\mathrm{df})$ & $\mathrm{p}$ & Post hoc \\
\hline$P_{\text {MAX }}\left(\mu \mathrm{mol} \mathrm{O} \mathrm{Cm}^{-2} \mathrm{~h}^{-1}\right)$ & $\begin{array}{l}\text { State } \\
\text { Treatment } \\
\text { State } \times \text { Treatment }\end{array}$ & $\begin{array}{l}11(2,29) \\
6.9(1,29) \\
1.8(2,29)\end{array}$ & $\begin{array}{r}<0.01 \\
<0.05 \\
0.19\end{array}$ & $\begin{array}{l}\mathrm{L}<\mathrm{M}=\mathrm{H} \\
600<1200 \text { for } \mathrm{L}, \mathrm{M}, \mathrm{H} \\
-\end{array}$ \\
\hline$E_{K}\left(\mu \mathrm{mol}\right.$ photons $\left.\mathrm{m}^{-2} \mathrm{~s}^{-1}\right)$ & $\begin{array}{l}\text { State } \\
\text { Treatment } \\
\text { State } \times \text { Treatment } \\
\text { Time } \\
\text { State } \times \text { Time } \\
\text { Treatment } \times \text { Time } \\
\text { State } \times \text { Treatment } \times \text { Time }\end{array}$ & $\begin{array}{r}0.24(2,29) \\
23(1,29) \\
5.7(2,29) \\
0.03(1,29) \\
0.33(2,29) \\
0.02(1,29) \\
0.03(2,29)\end{array}$ & $\begin{array}{r}0.79 \\
<0.01 \\
<0.01 \\
0.86 \\
0.72 \\
0.90 \\
0.97\end{array}$ & $\begin{array}{l}- \\
\text { na } \\
\text { L \& M, } 1200>600 \\
- \\
- \\
- \\
-\end{array}$ \\
\hline$R_{D A R K}\left(\mu \mathrm{mol} \mathrm{O} \mathrm{cm}^{-2} \mathrm{~h}^{-1}\right)$ & $\begin{array}{l}\text { State } \\
\text { Treatment } \\
\text { State } \times \text { Treatment } \\
\text { Time } \\
\text { State } \times \text { Time } \\
\text { Treatment } \times \text { Time } \\
\text { State } \times \text { Treatment } \times \text { Time }\end{array}$ & $\begin{array}{r}22(2,29) \\
2.6(1,29) \\
0.71(2,29) \\
19(1,29) \\
0.53(2,29) \\
4.7(1,29) \\
0.21(2,29)\end{array}$ & $\begin{array}{r}<0.01 \\
0.12 \\
0.50 \\
<0.01 \\
0.59 \\
<0.05 \\
0.81\end{array}$ & $\begin{array}{l}\mathrm{L}<\mathrm{M}=\mathrm{H} \\
- \\
- \\
\text { na } \\
- \\
\text { AM }<\text { PM when } E_{M A X}=1200 \\
-\end{array}$ \\
\hline
\end{tabular}

As expected, the shape of the PI curve for colonies of Turbinaria mesenterina varied with photoacclimation state. $P_{M A X}$ was significantly lower for corals acclimated to low light levels compared with the other 2 growth irradiances (main effect of State for $P_{\text {MAX, }}$ Table 1). $P_{\text {MAX }}$ was also higher under exposure to more intense light for corals acclimated to all growth irradiances (main effect of Treatment, Table 1). This latter finding indicates that photosynthesis did not reach complete saturation under the lower diurnal irradiance cycle (also evident from the filled points in Fig. 1D-F). $E_{K}$ increased with acclimation irradiance when corals were exposed to low light levels, but not under exposure to high light levels (Fig. 2A,B). This difference was apparent as a significant State $\times$ Treatment interaction (Table 1). To our knowledge, this finding represents the first evidence that corals dynamically downregulate net oxygen evolution due to excessive light absorption. We found no evidence of any variation in $E_{K}$ between morning and afternoon (all effects involving Time were non-significant for $E_{K}$, Table 1 ; filled points compared to triangles, Fig. 2A,B).

$R_{D A R K}$ was markedly influenced by light intensity, both in terms of acclimation irradiance (significant main effect of State, Table 1) and diurnal irradiance treatment. Under both diurnal irradiance cycles, $R_{D A R K}$ increased with acclimation irradiance (Fig. 2C,D). Fur- thermore, $R_{D A R K}$ was distinctly higher in the afternoon than in the morning under the high diurnal irradiance treatment (open triangles compared to filled points in Fig. 2D), but not under exposure to lower light levels

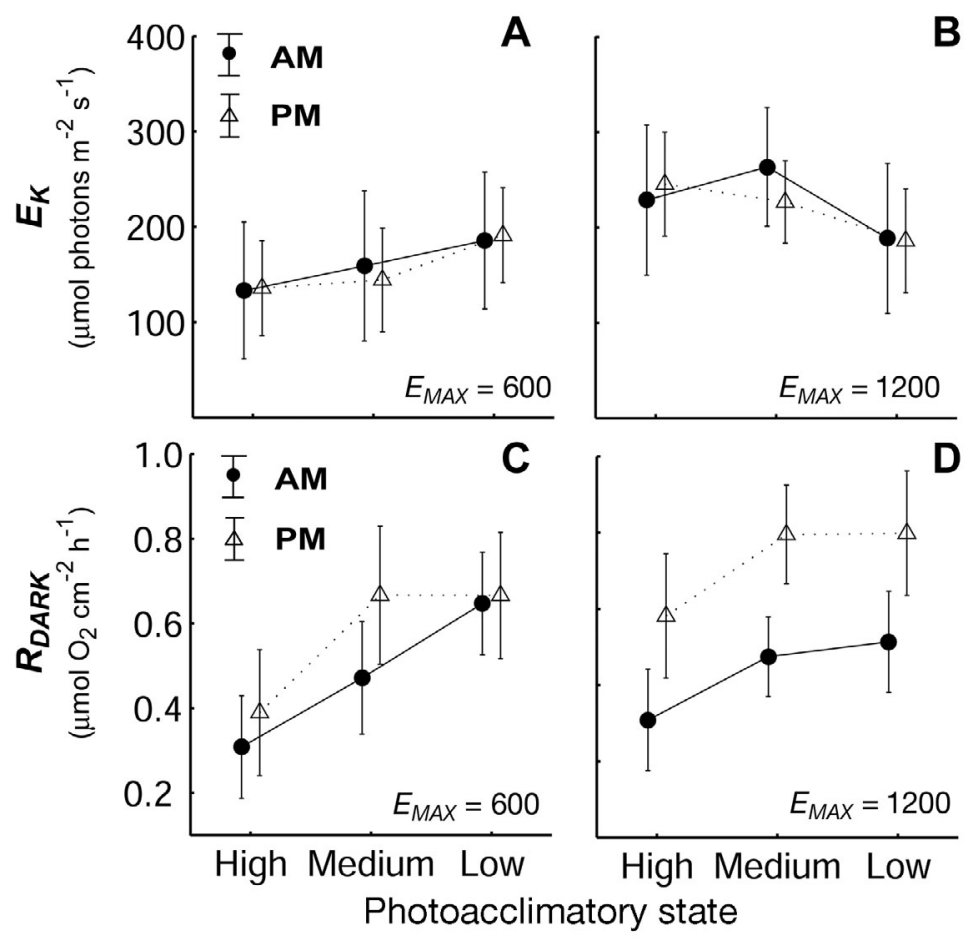

Fig. 2. Turbinaria mesenterina. $(\mathrm{A}, \mathrm{B})$ Sub-saturation irradiance $\left(E_{K}\right)$, and $(\mathrm{C}, \mathrm{D})$ respiration $\left(R_{D A R K}\right)$ during morning $(\mathrm{AM})$ and afternoon $(\mathrm{PM})$ in corals acclimated to 3 light regimes (low, medium, high) and exposed to 2 irradiance cycles (mean $\pm 95 \%$ confidence intervals; $\mathrm{n}=5$ to 8 ) 
(Fig. 2C). Consequently, we found a significant Treatment $\times$ Time interaction for $R_{\text {DARK }}$ (Table 1 ). Therefore, differences between rates of net photosynthesis in the early morning compared with the late afternoon at the same irradiance (Fig. 1E,F) are predominantly due to changes in rates of respiration. The post-illumination increase in rates of dark respiration was consistent across all photoacclimation groups (i.e. none of the interaction effects involving State were significant for $R_{D A R K}$, see Table 1). This suggests that increased metabolic activity following light exposure may be a general response of the coral-zooxanthellae symbiosis, and is not influenced by the degree to which exposure irradiance exceeds the irradiance to which corals are acclimated.

\section{Cost of photoinhibition}

Total net oxygen evolution (and equivalently, carbon fixation) was significantly lower during the afternoon than in the morning for corals acclimated to all 3 irradiance regimes when exposed to the higher daily irradiance cycle. Specifically, integrated rates of net photosynthesis under exposure to high light levels showed a 15 to $17 \%$ decline in the afternoon, compared with the morning (Fig. 3A; Table 2). Moreover, corals acclimated to the lowest light levels showed a $6 \%$ reduction in integrated net rates of photosynthesis during the afternoon when exposed to the lower daily irradiance regime. Although this reduction constitutes a considerable proportion of daily photosynthetic activity, gross photosynthetic energy acquisition (disregarding oxygen consumption through respiration) summed over the morning and the afternoon did not differ significantly for any of the comparisons (Fig. 3B; Table 2). In other words, photoinhibition only represents a significant energetic cost for corals if metabolic activity associated with repair of damaged components of the

Table 2. Turbinaria mesenterina. Proportional difference between integrated net and gross photosynthesis over the course of the afternoon compared to the morning for corals acclimated to 3 different light regimes (State), and exposed to 2 diurnal irradiance cycles (maximum daily irradiance, $E_{M A X}$ $\mu \mathrm{mol}$ photons $\mathrm{m}^{-2} \mathrm{~s}^{-1}$ ). Results of paired samples $t$-test

\begin{tabular}{|llcrrrr|}
\hline \multirow{2}{*}{$E_{\text {MAX }}$} & State & df & \multicolumn{3}{c}{ Net photosyn. } & \multicolumn{2}{c|}{ Gross photosyn. } \\
& & & $t$ & $\mathrm{p}$ & \multicolumn{1}{c}{$t$} & $\mathrm{p}$ \\
\hline 600 & High & 5 & -0.07 & 0.95 & -0.06 & 0.96 \\
& Medium & 4 & -1.99 & 0.12 & 0.51 & 0.64 \\
& Low & 5 & -3.37 & $<0.05$ & -0.15 & 0.89 \\
1200 & High & 4 & 4.4 & $<0.05$ & 0.09 & 0.93 \\
& Medium & 7 & -4.5 & $<0.05$ & 0.71 & 0.50 \\
& Low & 4 & -7.6 & $<0.05$ & -0.31 & 0.77 \\
\hline
\end{tabular}

photosynthetic apparatus is the major cause of postillumination enhancement of respiration.

Although daily costs of photoinhibition appear to be negligible for Turbinaria mesenterina, photoacclimation to high light levels does not maximise integrated daily photosynthesis. In fact, total daily energy acquisition per unit surface area was lower on average for the high light acclimated corals than for corals acclimated to intermediate light levels when exposed to the same daily irradiance cycle (Fig. 4). This is primarily due to a lower chlorophyll concentration, higher $E_{K}$ and a higher $R_{D A R K}$ for corals at high light levels, compared to those acclimated to lower light levels. When integrated photosynthesis was calculated for each photoacclimation treatment over a daily irradiance cycle with $E_{M A X}$ equal to the growth irradiance, results indicated that higher light availability does not translate to higher daily carbon acquisition for $T$. mesenterina. In other words, photoacclimation causes carbon acquisition to remain constant across an approximately 5 -fold light gradient.

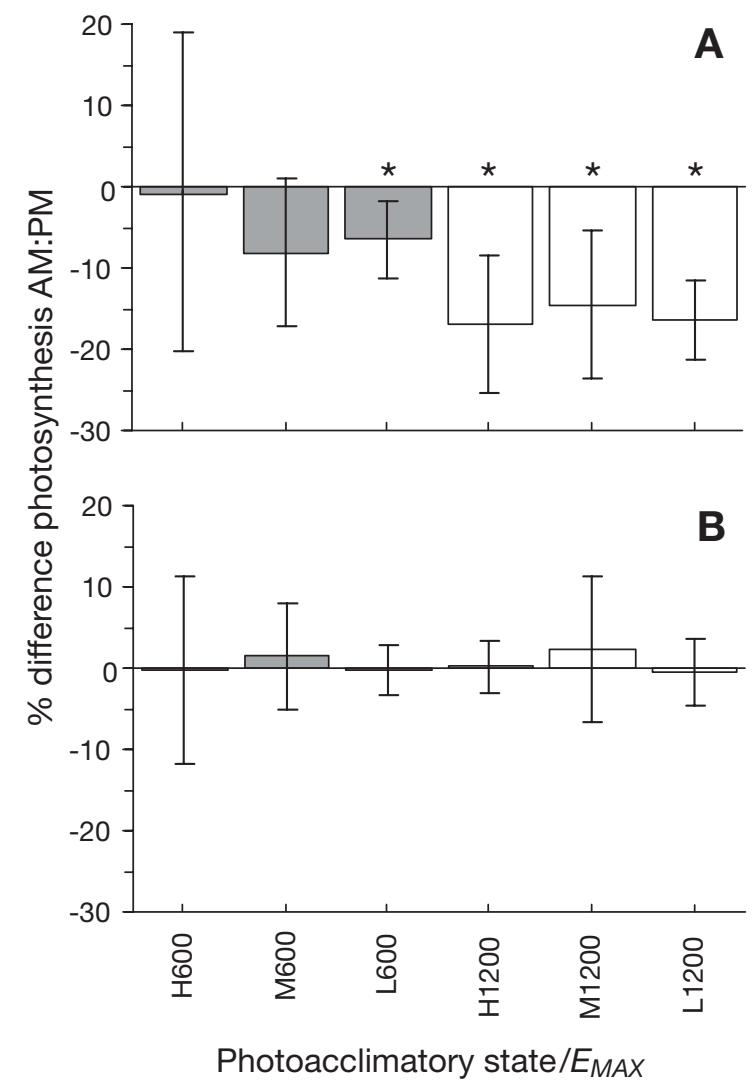

Fig. 3. Turbinaria mesenterina. Percentage difference in (A) net and (B) gross photosynthesis between morning and afternoon in corals acclimated to 3 different light regimes $(\mathrm{H}$ : high; M: medium; L: low) and exposed to 2 diurnal irradiance cycles $\left(E_{M A X}, 600\right.$ and $1200 \mu$ mol photons $\left.\mathrm{m}^{-2} \mathrm{~s}^{-1}\right)($ mean $\pm \mathrm{SE} ; \mathrm{n}=5$ to 8 ). ${ }^{*}$ Statistically significant difference (dependent samples t-test, see Table 3) 


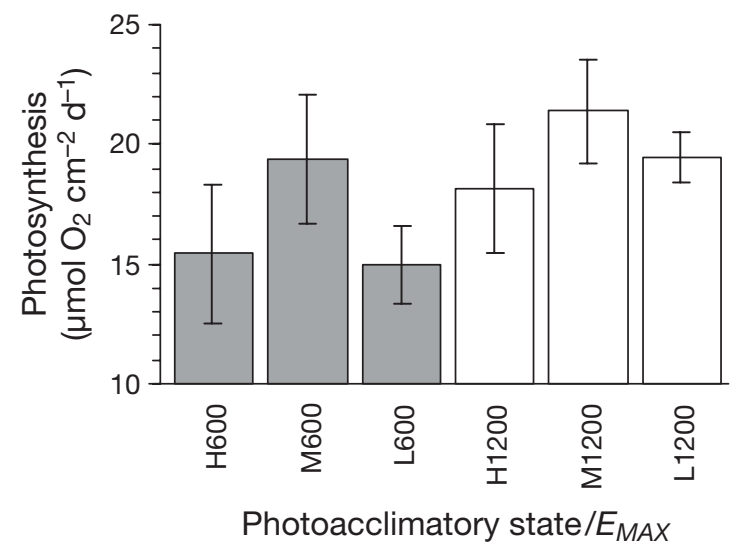

Fig. 4. Turbinaria mesenterina. Daily integrated photosynthetic oxygen evolution in corals acclimated to 3 light regimes (H: high; M: medium; L: low) and exposed to 2 diurnal irradiance cycles $\left(E_{M A X}, 600\right.$ and $1200 \mu \mathrm{mol}$ photons $\left.\mathrm{m}^{-2} \mathrm{~s}^{-1}\right)$ $($ mean $\pm \mathrm{SD})$

To determine the medium-term consequences of photoinhibition and changes in photoacclimation state on carbon gain, we repeated measurements of photosynthesis for the low light acclimated corals over $3 \mathrm{~d}$ of exposure to a daily irradiance cycle with $E_{M A X}=$ $1200 \mu \mathrm{mol}$ photons $\mathrm{m}^{-2} \mathrm{~s}^{-1}$. Although all of the measured photosynthetic properties varied over this time frame (Table 3), changes were only statistically significant for chlorophyll concentration and light-saturated $P_{\text {MAX }}$. The increase in (fitted) $P_{M A X}$ was partially due to a corresponding increase in $R_{D A R K}$. The net effect of this was that although $P_{\text {MAX }}$ was higher after repeated exposure to high light levels, integrated daily photosynthesis was actually lower, although not significantly so. In general, these changes in photosynthetic properties were consistent with photoacclimation to high light levels (increased $P_{M A X}, E_{K}$ and $R_{D A R K}$, lower chlorophyll concentration and maximum photochemical efficiency). Collectively, our results indicate that while gradual loss of function of individual symbionts over the course of the day has a negligible (short-term) impact on energy budgets, repeated exposure leads to lower concentration of chlorophyll per unit surface, and consequently lower daily energy acquisition in the long term.

\section{Fluorescence versus respirometry}

In contrast to the linear relationship between fluorescence and gas exchange measures of photosynthetic activity typically assumed for corals (e.g. Brown et al. 1999, Hoegh-Guldberg \& Jones 1999), our results demonstrate a curvilinear relationship (Fig. 5). Furthermore, there was considerable variability in the relationship between the quantum yields of oxygen evolution and photochemistry (Fig. 5A). At high light levels, ETR may decline by $>50 \%$ without any measurable effect on the net rate of photosynthesis. Similarly, a 3-fold variation in rETR was evident at $P_{M A X}$. On the other hand, rETR was directly proportional to rates of oxygen evolution at low light levels (i.e. low rates of photosynthesis). The breakdown of the linear relationship between these 2 measures at high irradiance is driven by the substantially greater degree of hysteresis exhibited by rETR versus irradiance compared with photosynthesis versus irradiance when measured over a diurnal cycle. In addition to the hysteresis effect, lower correlation at high irradiance was related to variation in $P_{\text {MAX }}$ (oxygen evolution) due to photoacclimation. For corals acclimated to low light levels, oxygen evolution per electron transported was lower (lower rate of photosynthesis at the same rETR, Fig. 5B). Collectively, these results demonstrate that for Turbinaria mesenterina, the relationship between biochemical and energetic assays of photosynthesis is influenced by the photoacclimation state of individual colonies, even when variation in chlorophyll concentration between colonies is taken into account.

\section{DISCUSSION}

Our results demonstrate that exposure of corals to high light levels only leads to a depression of net photosynthesis when average daily irradiances are much higher than growth (acclimation) irradiances. Moreover, reduced rates of net photosynthesis in the afternoon are primarily associated with increased respiration rates. Previous studies of light-enhanced respiration in corals have demonstrated a 6- to 12 -fold

Table 3. Turbinaria mesenterina. Change in photosynthetic properties (mean \pm SE) in corals acclimated to low light following repeated exposure to excessive irradiance $\left(E_{M A X}=1200 \mu \mathrm{mol}\right.$ photons $\left.\mathrm{m}^{-2} \mathrm{~s}^{-1}\right)$, and results of dependent samples $t$-test $(\mathrm{df}=3)$. $E_{K}$ : sub-saturation irradiance; $P_{\text {MAX: }}$ maximum rate of photosynthesis; $R_{D A R K}$ : rate of respiration in darkness; $F_{\mathrm{v}} / F_{\mathrm{m}}:$ maximum quantum yield of photochemistry

\begin{tabular}{|c|c|c|c|c|c|}
\hline & $\begin{array}{l}\text { Chlorophyll } \\
\left(\mu \mathrm{g} \mathrm{cm}^{-2}\right)\end{array}$ & $\begin{array}{c}E_{K} \\
\left(\mu \mathrm{mol} \text { photons } \mathrm{m}^{-2} \mathrm{~s}^{-1}\right)\end{array}$ & 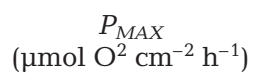 & 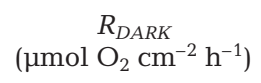 & $F_{\mathrm{v}} / F_{\mathrm{m}}$ \\
\hline Day 1 & $32 \pm 6$ & $229 \pm 36$ & $2.3 \pm 0.06$ & $0.29 \pm 0.17$ & $0.66 \pm 0.03$ \\
\hline Day 3 & $23 \pm 8$ & $345 \pm 54$ & $2.6 \pm 0.06$ & $0.40 \pm 0.10$ & $0.52 \pm 0.06$ \\
\hline$t$ & 3.3 & -2.1 & -7.8 & 0.63 & 2.4 \\
\hline $\mathrm{p}$ & $<0.05$ & 0.13 & $<0.01$ & 0.57 & 0.10 \\
\hline
\end{tabular}



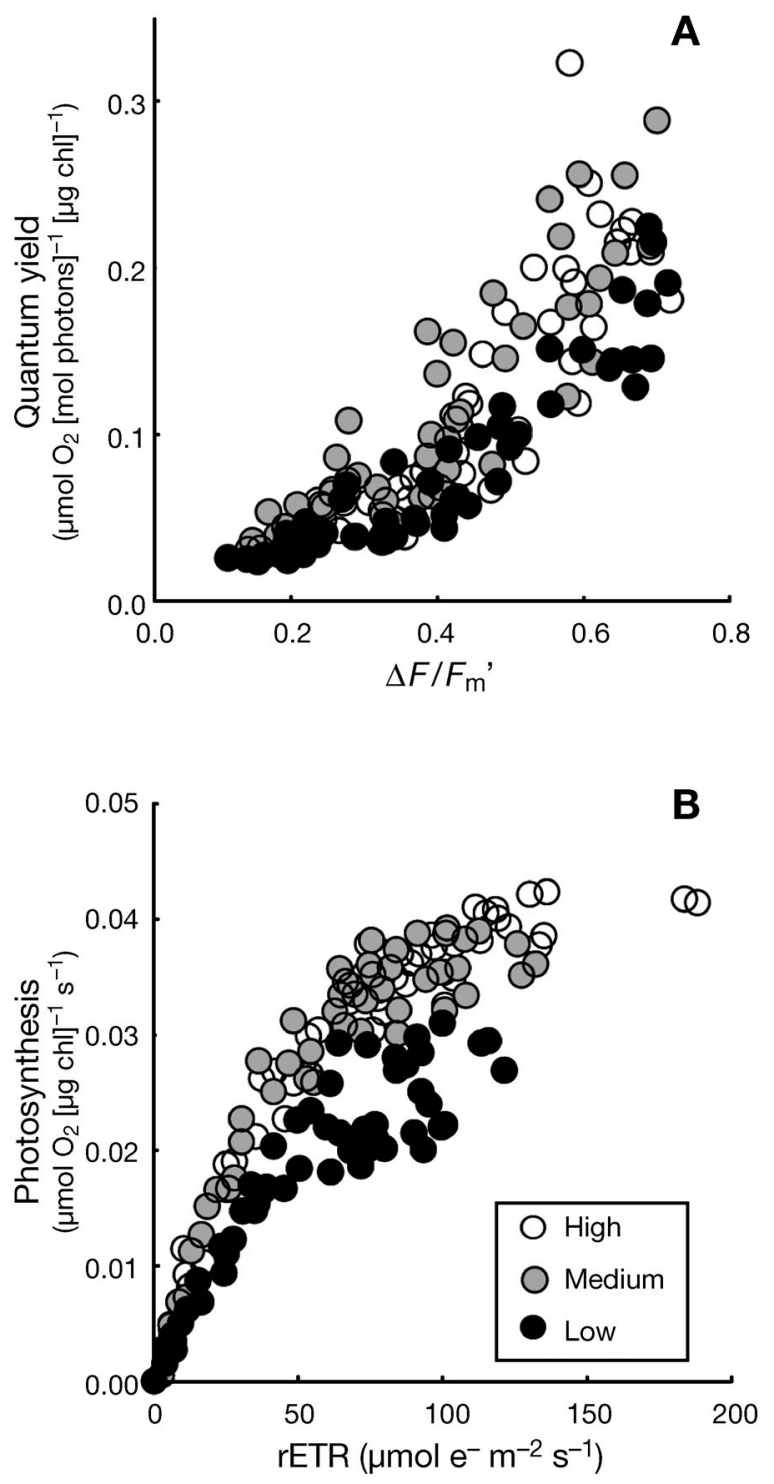

Fig. 5. Turbinaria mesenterina. Comparison between respirometry and fluorescence assays of photosynthetic activity. (A) Quantum yield of oxygen evolution (normalized to chlorophyll concentration) versus photochemical yield, and (B) rate of photosynthesis (corrected for dark respiration) versus relative electron transport rate, in corals acclimated to 3 light regimes (high, medium, low). Data are means; error bars omitted for clarity ( $\mathrm{n}=5$ to 8 )

increase in oxygen consumption following light exposure (Kuhl et al. 1995, Al-Horani et al. 2003). A proportion of this increase may reflect energy expenditure for repair of damage to the photosynthetic apparatus of zooxanthellae, and/or coral tissue damage. However, light-enhanced respiration in corals is more likely due to enhanced metabolic activity related to e.g. increased skeletal growth (e.g. Reynaud-Vaganay et al. 2001) and increased photosynthetic activity, as significant light enhancement of respiration has been measured in corals exposed to irradiances as low as $140 \mu \mathrm{mol}$ photons $\mathrm{m}^{-2} \mathrm{~s}^{-1}$ (Al-Horani et al. 2003). If increased rates of respiration following exposure to high light levels were predominantly due to costs of repair of the photosynthetic apparatus, the magnitude of the change in respiration between morning and afternoon would depend upon the degree to which exposure irradiance exceeded acclimation irradiance (damage being greater for corals acclimated to lower light levels). As we observed the same post-illumination increase in rates of respiration for all acclimation treatments following exposure to the same diurnal irradiance cycle, we conclude that daily energetic costs of photoinhibition in corals are negligible.

Dissipation of light through non-photochemical pathways is recognised as an effective photoprotective mechanism in corals (e.g. Hoegh-Guldberg \& Jones 1999, Gorbunov et al. 2001), and the same mechanism is present in other photosynthetic organisms for which energetic costs of photoinhibition are apparent (e.g. higher plants and phytoplankton; see Pahl-Wostl 1992, Werner et al. 2001). Our results raise the question as to how corals avoid these costs. Coral tissue contains amino acids that absorb, reflect or fluoresce ultraviolet light (mycosporine-like amino acids or MAAs; Jokiel \& York 1982), and pigments that absorb light over photosynthetic wavelengths (Salih et al. 2000, Dove 2004). Therefore, the coral tissue layer may act as a protective screen for the zooxanthellae. Indeed, there is some evidence that host tissue reduces the light levels reaching symbionts by $>50 \%$ in some marine organisms (e.g. hydroids; Fitt \& Cook 2001). Alternatively, zooxanthellae may shade each other, with symbionts in the upper tissue layers shielding those in lower layers. Zooxanthellae in different parts of a coral colony experience different light environments (Jones et al. 2000), and vary in their chlorophyll fluorescence characteristics (Hill et al. 2004). Moreover, histology of bleached corals has revealed a greater loss of zooxanthellae from upper tissue layers as opposed to deeper tissues (Brown et al. 1995). Therefore, although zooxanthellae in upper tissue layers may suffer reduced rates of photosynthesis due to photoinhibition, those in lower layers are likely to remain protected and potentially compensate for the reduced photosynthesis of the upper layers.

If zooxanthellae do indeed shade each other, then the use of fluorometry to measure photosynthesis in corals may return biased results. For instance, in microphytobenthic assemblages, the thickness of the fluorescing layer has a pronounced impact on measured photochemical efficiency, with values overestimated by up to $60 \%$ in thick biofilms (Forster \& Kromkamp 2004). An equivalent phenomenon may explain our findings of lower oxygen evolution per electron transported for corals acclimated to low light 
levels compared with medium- and high-light acclimated colonies. Self-shading of zooxanthellae would result in overestimation of apparent photochemical efficiency as the measured efficiency of the upper layer would be augmented by higher efficiency of symbionts exposed to lower light levels deeper in the tissue. This would in turn lead to overestimation of rETR, and an apparently lower rate of oxygen evolution per electron transported through PSII. Overall, our findings indicate that future studies should take account of tissue properties of corals, such as symbiont density, tissue thickness and presence of other light-absorbing pigments, when interpreting fluorescence assays of photochemistry.

Due to the insensitivity of rates of net photosynthesis to supra-saturating light levels, we find that photochemical electron transport (in zooxanthellae) and photosynthetic oxygen evolution (in the coral-zooxanthellae symbiosis) correlate poorly at high light levels; under midday irradiances, even very low photochemical efficiencies (and high NPQ) do not necessarily result in reduced rates of photosynthesis. Because the fluorescence behavior of Turbinaria mesenterina is consistent with that of several other species (e.g. Goniastrea aspera: Brown et al. 1999; Stylophora pistillata: Jones \& Hoegh-Guldberg 2001, Winters et al. 2003), our findings are likely to reflect general properties of the coral-zooxanthellae symbiosis. Moreover, our results demonstrate that the influence of non-assimilatory electron flow at high irradiances on the relationship between fluorescence and respirometry assays of photosynthesis may represent a general trend for photosynthetic organisms. We find that for corals, oxygen evolution saturates prior to rETR, as has been shown for cyano-lichens, macroalgae and higher plants (Sundberg et al. 1997, Fryer et al. 1998, Figueroa et al. 2003). This indicates that once the assimilatory reactions of photosynthesis become saturated, electrons may still be transported through PSII. The importance of electron sinks in addition to $\mathrm{CO}_{2}$ reduction for avoidance of photoinhibition has been noted previously (Krall \& Edwards 1992, Hoegh-Guldberg \& Jones 1999), with photorespiration and the Mehler cycle as the most obvious candidates for non-photosynthetic electron transport (see Fryer et al. 1998, Figueroa et al. 2003). It is clear that for a range of photosynthetic organisms, including corals, a decline in rETR at high light levels is not representative of a decline in photosynthetic oxygen evolution.

Despite the negligible costs associated with photoinhibition on a daily basis, repeated exposure to high irradiance does have a negative impact on photosynthetic energy acquisition in corals. Cell damage caused by prolonged exposure to ultraviolet light represents an additional factor that may inhibit coral growth in shallow (high light) habitats (e.g. Jokiel \& York 1982), although there is some evidence that higher concentrations of MAAs in corals from shallow water may be sufficient to mitigate the effects of ultraviolet light on rates of photosynthesis (Shick et al. 1995). Clearly, colonies of Turbinaria mesenterina acclimated to high light levels would have greater daily energy acquisition if they had higher symbiont population densities, lower $E_{K}$ and higher $P_{M A X}$. Although our results demonstrate that there are negligible energetic costs associated with short-term (1 d) exposure to excessive irradiance, that the abovementioned combination of photosynthetic properties does not occur is evidence that avoiding damage to the photosynthetic apparatus is a fundamental component of acclimation to high light environments. This conclusion is supported by our observation of a reduction in chlorophyll concentration for low light acclimated corals following repeated exposure to excessive irradiance. Continued reduction of chlorophyll concentration through time must eventually lead to a reduced daily energy acquisition per unit area of colony (e.g. daily integrated photosynthesis of high light acclimated corals compared with medium light acclimated corals in this study). Our results indicate that costs of photoinhibition in corals are manifest over time scales of days to weeks, rather than being apparent over a diurnal irradiance cycle as observed in other taxa (e.g. Platt et al. 1980, Ogren \& Sjostrom 1990). These findings are consistent with recent observations of seasonal fluctuations in photosynthetic activity of several Caribbean coral species (Warner et al. 2002), and also explain why a moderate decrease in light availability within habitats either has no effect on photosynthetic energy acquisition for corals, or leads to higher photosynthesis for colonies from shaded habitats (Titlyanov 1991b). The trade-off between efficient utilization of light for photosynthesis and avoidance of cumulative damage to the photosynthetic apparatus due to repeated exposure to excessive irradiance means that higher light availability does not equate to higher energy acquisition.

Overall, changes in the photochemical activity of zooxanthellae over a diurnal irradiance cycle do not cause a reduction in photosynthetic energy acquisition for coral colonies. Photoinhibition in corals is manifested through a different mechanism than in other photosynthetic organisms. For some species of microalgae, energetic costs of photoinhibition become apparent through decreased $P_{M A X}$ under exposure to light levels comparable to those used in this study (e.g. Platt et al. 1980, Pahl-Wostl et al. 1992), or through reduced photosynthetic efficiency following high light exposure that causes a reduction in rates of photosynthesis (e.g. Kana et al. 2002). In contrast, energetic costs of photoinhibition in corals become apparent as a gradual reduction in photosynthetic capacity over time (several days) 
following repeated exposure to excessive irradiance. These results indicate that, in corals, long-term rather than diurnal changes in photosynthetic properties are the key to understanding ecological impacts of environmental gradients in light intensity.

Acknowledgements. This study was funded by the Australian Research Council and James Cook University. We thank M. Dornelas, D. Abrego and J. Cox for their assistance with field and laboratory work. This study is a contribution from the ARC Centre of Excellence for Coral Reef Studies.

\section{LITERATURE CITED}

Al-Horani FA, Al-Moghrabi SM, de Beer D (2003) Microsensor study of photosynthesis and calcification in the scleractinian coral Galaxea fascicularis: active internal carbon cycle. J Exp Mar Biol Ecol 288:1-15

Anthony KRN, Hoegh-Guldberg O (2003) Kinetics of photoacclimation in corals. Oecologia 134:23-31

Anthony KRN, Hoogenboom MO, Connolly SR (2005) Adaptive variation in coral geometry and the optimisation of internal colony light climates. Funct Ecol 19:17-26

Brown BE, Ambarsari I, Warner ME, Fitt WK, Dunne RP, Gibb SW, Cummings DG (1999) Diurnal changes in photochemical efficiency and xanthophyll concentrations in shallow water reef corals: evidence for photoinhibition and photoprotection. Coral Reefs 18:99-105

Brown BE, Le Tissier MDA, Bythell JC (1995) Mechanisms of bleaching deduced from histological studies of reef corals sampled during a natural bleaching event. Mar Biol 122: 655-663

Demmig-Adams B, Adams WW (1992) Photoprotection and other responses of plants to high light stress. Annu Rev Plant Physiol Plant Mol Biol 43:599-626

Dove S (2004) Scleractinian corals with photoprotective host pigments are hypersensitive to thermal bleaching. Mar Ecol Prog Ser 272:99-116

Edmunds PJ, Spencer-Davies P (1988) Post-illumination stimulation of respiration rate in the coral Porites porites. Coral Reefs 7:7-9

Falkowski PG, Raven JA (1997) Aquatic photosynthesis. Blackwell, Malden, MA

Figueroa FL, Conde-Alvarez R, Gomen I (2003) Relations between electron transport rates determined by pulse amplitude modulated chlorophyll fluorescence and oxygen evolution in macroalgae under different light conditions. Photosynth Res 75:259-275

Fitt WK, Cook CB (2001) Photoacclimation and the effect of the symbiotic environment on the photosynthetic response of symbiotic dinoflagellates in the tropical marine hydroid Myrionema amboinense. J Exp Mar Biol Ecol 256:15-31

Forster RM, Kromkamp JC (2004) Modelling the effects of chlorophyll fluorescence from subsurface layers on photosynthetic efficiency measurements in microphytobenthic algae. Mar Ecol Prog Ser 284: 9-22

Fryer MJ, Andrews JR, Oxborough K, Blowers DA, Baker NR (1998) Relationship between $\mathrm{CO}_{2}$ assimilation, photosynthetic electron transport, and active $\mathrm{O}_{2}$ metabolism in leaves of maize in the field during periods of low temperature. Plant Physiol 116:571-580

Genty B, Briantais JM, Baker NR (1989) The relationship between the quantum yield of photosynthetic electron transport and quenching of chlorophyll fluorescence. Biochim
Biophys Acta 990:87-92

Goiran C, Al-Moghrabi SM, Allemand D, Jaubert J (1996) Inorganic carbon uptake for photosynthesis by the symbiotic coral/dinoflagellate association. I. Photosynthetic performance of symbionts and dependence on sea water bicarbonate. J Exp Mar Biol Ecol 199:207-225

Gorbunov MY, Kolber ZS, Lesser MP, Falkowski PG (2001) Photosynthesis and photoprotection in symbiotic corals. Limnol Oceanogr 46:75-85

Hill R, Schreiber U, Gademann R, Larkum AWD, Kuhl M, Ralph PJ (2004) Spatial heterogenetity of photosynthesis and the effect of temperature-induced bleaching conditions in 3 species of corals. Mar Biol 144:633-640

Hoegh-Guldberg O, Jones RJ (1999) Photoinhibition and photoprotection in symbiotic dinoflagellates from reefbuilding corals. Mar Ecol Prog Ser 183:73-86

Iglesias-Prieto R, Trench RK (1994) Acclimation and adaptation to irradiance in symbiotic dinoflagellates. I. Responses of the photosynthetic unit to changes in photon flux density. Mar Ecol Prog Ser 113:163-175

Iglesias-Prieto R, Beltran VH, LaJeunesse TC, Reyes-Bonilla $H$, Thome PE (2004) Different algal symbionts explain the vertical distribution of dominant reef corals in the eastern Pacific. Proc R Soc Lond Ser B 271:1757-1763

Jeffrey SW, Humphrey GF (1975) New spectrophotometric equations for determining chlorophylls $a, b, c$ and $c 2$ in higher plants, algae and natural phytoplankton. Biochim Biophys Acta 167:191-194

Jokiel PL, York RH Jr (1982) Solar ultraviolet photobiology of the reef coral Pocillopora damicornis and symbiotic zooxanthellae. Bull Mar Sci 32:301-315

Jones RJ, Hoegh-Guldberg O (2001) Diurnal changes in the photochemical efficiency of the symbiotic dinoflagellates (Dinophyceae) of corals: photoprotection, photoinactivation and the relationship to coral bleaching. Plant Cell Environ 24:89-99

Jones RJ, Ward S, Yang Amri A, Hoegh-Guldberg O (2000) Changes in quantum efficiency of Photosystem II of symbiotic dinoflagellates of corals after heat stress, and of bleached corals sampled after the 1998 Great Barrier Reef mass bleaching event. Mar Freshw Res 51:63-71

Kana R, Lazar D, Prasil O, Naus J (2002) Experimental and theoretical studies on the excess capacity of Photosystem II. Photosynth Res 72:271-284

Krall JP, Edwards GE (1992) Relationship between photosystem II activity and $\mathrm{CO}_{2}$ fixation in leaves. Physiol Plant 86:180-187

Kuhl M, Cohen Y, Dalsgaard T (1995) Microenvironment and photosynthesis of zooxanthellae in scleractinian corals studied with microsensors for $\mathrm{O}_{2}, \mathrm{pH}$ and light. Mar Ecol Prog Ser 117:159-172

Laing WA, Greer DH, Schnell TA (1995) Photoinhibition of photosynthesis causes a reduction in vegetative growth rates of dwarf bean (Phaseolus vulgaris) plants. Aust J Plant Physiol 22:511-520

Lesser MP, Gorbunov MY (2001) Diurnal and bathymetric changes in chlorophyll fluorescence yields of reef corals measured in situ with a fast repetition rate fluorometer. Mar Ecol Prog Ser 212:69-77

Levy O, Dubinsky Z, Schneider K, Achituv Y, Zakai D, Gorbunov MY (2004) Diurnal hysteresis in coral photosynthesis. Mar Ecol Prog Ser 268:105-117

Marra J (1978) Effect of short-term variations in light intensity on photosynthesis of a marine phytoplankter: a laboratory simulation study. Mar Biol 46:191-202

Maxwell K, Badger MR, Osmond CB (1998) A comparison of $\mathrm{CO}_{2}$ and $\mathrm{O}_{2}$ exchange patterns and the relationship with 
chlorophyll fluorescence during photosynthesis in C3 and CAM plants. Aust J Plant Physiol 25:45-52

Maxwell K, Johnson GN (2000) Chlorophyll fluorescencea practical guide. J Exp Bot 51:659-668

Muko S, Kawasaki K, Sakai K (2000) Morphological plasticity in the coral Porites sillimaniani and its adaptive significance. Bull Mar Sci 66:225-239

Muscatine L, McCloskey LR, Marian RE (1981) Estimating the daily contribution of carbon from zooxanthellae to coral animal respiration. Limnol Oceanogr 26(4):601-611

Ogren E, Sjostrom M (1990) Estimation of the effect of photoinhibition on the carbon gain in leaves of a willow canopy. Planta 181:560-567

Oliver JK, Chalker BE, Dunlap WC (1983) Bathymetric adaptations of reef-building corals at Davies Reef, Great Barrier Reef, Australia. I. Long-term growth responses of Acropora formosa (Dana 1846). J Exp Mar Biol Ecol 73: 11-35

Pahl-Wostl C (1992) Dynamic versus static models for photosynthesis. Hydrobiologia 238:189-196

Platt T, Gallegos CL, Harrison WG (1980) Photoinhibition of photosynthesis in natural assemblages of marine phytoplankton. J Mar Res 38:687-701

Reynaud-Vaganay S, Juillet-Leclerc A, Jaubert J, Gatusso JP (2001) Effect of light on skeletal ${ }^{13} \mathrm{C}$ and ${ }^{18} \mathrm{O}$ and interaction with photosynthesis, respiration and calcification in 2 zooxanthellate scleractinian corals. Paleogeogr Palaeoclimatol Palaeoecol 175:393-404

Salih A, Larkum A, Cox G (2000) Fluorescent pigments in corals are photoprotective. Nature 408:850-853

Seaton GGR, Walker DA (1990) Chlorophyll fluorescence as a

Editorial responsibility: Howard I. Browman (Associate Editor-in-Chief), Storebø, Norway measure of photosynthetic carbon assimilation. Proc R Soc Lond Ser B 242:29-35

Shick JM, Lesser MP, Dunlap WC, Stochaj WR, Chalker BE, Won JW (1995) Depth-dependent responses to solar ultraviolet radiation and oxidative stress in the zooxanthellate coral Acropora microphthalma. Mar Biol 122:41-51

Sundberg B, Campbell D, Palmqvist K (1997) Predicting $\mathrm{CO}_{2}$ gain and photosynthetic light acclimation from fluorescence yield and quenching in cyano-lichens. Planta 201: 138-145

Titlyanov EA (1991a) Light adaptation and production characteristics of branches differing by age and illumination of the hermatypic coral Pocillopora verrucosa. Symbiosis 10: 249-261

Titlyanov EA (1991b) The stable level of coral primary production in a wide light range. Hydrobiologia 216/217: 383-387

Warner ME, Chilcoat GC, McFarland FK, Fitt WK (2002) Seasonal fluctuations in the photosynthetic capacity of photosystem II in symbiotic dinoflagellates in the Caribbean reef-building coral Montastrea. Mar Biol 141:31-38

Werner C, Ryel RJ, Correia O, Beyschlag W (2001) Effects of photoinhibition on whole-plant carbon gain assessed with a photosynthesis model. Plant Cell Environ 24:27-40

Willis BL (1985) Phenotypic plasticity versus phenotypic stability in the reef corals Turbinaria mesenterina and Pavona cactus. Proc 5th Int Coral Reef Symp 4:107-112

Winters G, Loya Y, Roettgers R, Beer S (2003) Photoinhibition in shallow-water colonies of the coral Stylophora pistillata as measured in situ. Limnol Oceanogr 48:1388-1393

Submitted: September 16, 2005; Accepted: December 27, 2005 Proofs received from author(s): March 29, 2006 